\title{
A DFT Study for Eliminating a Water Pollutant by Using an Adsorbent
}

\author{
Juan Horacio Pacheco Sánchez* and Rosario Suárez Reyes \\ Division of Postgraduate Studies and Research, Instituto Tecnológico de Toluc, México
}

*Corresponding author: Juan Horacio Pacheco Sánchez, Division of Postgraduate Studies and Research, Instituto Tecnológico de Toluc, México.

To Cite This Article: Juan Horacio Pacheco Sánchez, Juan Horacio Pacheco Sánchez. 2020 - 7(4). AJBSR.MS.ID.001174.

DOI: 10.34297/AJBSR.2020.07.001174

Received: 㭗 February 10, 2020; Published: 畊 February 24, 2020

\begin{abstract}
A pollutant on the water is an azoic dye molecule (adsorbate) within its corresponding ${ }^{-} \mathrm{O}_{3} \mathrm{~S}$ active site, and it can be relieved from water using

chitosan copolymer molecule (adsorbent) within its active site, which is an ion $\mathrm{NH}_{3}^{+}$of ammonia from amino group protonated. After DFT geometry optimization, the reactivity between these two active sites in acidic aqueous solutions can become either neutral acid form or two products (sulfur dioxide $\mathrm{SO}_{2}$ and $\mathrm{H}_{2} \mathrm{NOH}$ ). We infer the kind of adsorption established on the neutral acid form molecule.
\end{abstract}

\section{Introduction}

Our primary goal in here is to apply DFT to the interaction between chitosan (adsorbent) and azoic dye (adsorbate), through their reaction sites $\mathrm{NH}_{3}^{+}$(ion of ammonia from amino group protonated) and ${ }^{-} \mathrm{O}_{3} \mathrm{~S}$ (sulfur trioxide ion of sulfonate group) respectively, just to infer possible existing adsorption. This is done first calcu-

lating its geometry optimization between $\mathrm{NH}_{3}^{+}$and ${ }^{-} \mathrm{O}_{3} \mathrm{~S}$. The reaction among these molecular ions produces sulfamic acid which in

zwitterion form ${ }^{+} \mathrm{H}_{3} \mathrm{NSO}_{3}^{-}$is more stable than the neutral acid form $\mathrm{H}_{2} \mathrm{NSO}_{2} \mathrm{OH}$ in solid state [1-5]. Physical properties (structural and spectroscopic) and chemical reactions of sulfamic acid have been extensively reviewed [6-8]. The structure of both the zwitterion and neutral form has theoretically been studied previously [9-13]. We study here the neutral acid case as an isomer $\mathrm{HSO}_{3} \mathrm{NH}_{2}$.

Azo dyes are a class of synthetic dyes which when degraded in the bodies of water can cause the rupture of azo bond of amines, causing many harmful effects in some human organs such as the brain, liver, kidneys, central nervous system and reproductive system. Synthetic dyes also affect the photosynthetic activity of some aquifer's plants due to the presence of aromatics, metals, chlorides, etc. [14]. The discovery of synthetic dyes has limited the role of natural dyes due to its characteristics such as low production cost, brighter colors, better resistance to environmental factors and easy application. However synthetic dyes can be often highly toxic and carcinogenic [15]. The dyes have become a major source of severe water pollution as a result of the rapid development of many industries that use them in order to colorize their products [16]. Effects described by the pollution of azoic dyes mean a problem that requires attention and treatment.

Chitosan is a product of chitin, which is the second most abundant natural polysaccharide in nature. Chitosan can be obtained from partial deacetylation of chitin [17]. Among the many uses of chitosan products are nutraceuticals, food protectors, medical uses, agricultural uses, and many others. Application to water purification is in research. Chitosan is a polymer, its chemical structure as copolymer is drawn in (s 1a), which is the input for applying geometry optimization, and its output can be seen in (Figure 1b).

This copolymer chitosan is made up two units:

a. $\quad \beta$-(1-4)-2-acetamide-2-deoxy-D-glucopyranose

b. $\quad \beta$-(1-4)-2-amino-2-deoxy-D-glucopyranose. 
The former has a molecular weight of 203.2, $\mathrm{C}_{8} \mathrm{H}_{13} \mathrm{NO}_{4}$ formula, composition: C 47.3\%, H 6.4\%, N 6.9\% and $039.4 \%$; and the latter has a molecular weight of 161.1, $\mathrm{C}_{6} \mathrm{H}_{11} \mathrm{NO}_{4}$ formula, composition: C 44.7\%, H $6.9 \%$, N 8.7\%, 0 39.7\%. When chitosan is dissolved in an acidic medium the amino group is protonated, this fact generates a positive charge, while the azo dyes with sulfonate groups dissolved in water have a negative charge. Therefore, there are groups

$\mathrm{NH}_{3}^{+}$and ${ }^{-} \mathrm{O}_{3} \mathrm{~S}$, which have attracted to each other, giving rise to adsorption of azo dyes with sulfonic groups in the chitosan.

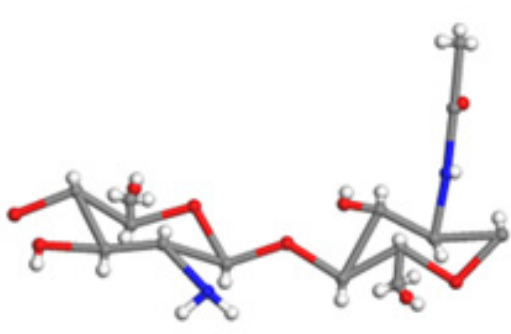

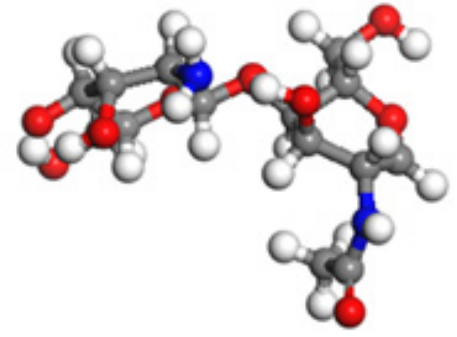

b

Figure 1: A molecular unit of chitosan: a) Chemical structure of copolymer chitosan. b) Optimized.

It is known the use of ammonia $\left(\mathrm{NH}_{3}\right)$ to remove sulfur dioxide $\left(\mathrm{SO}_{2}\right)[18,19]$. Some researchers $[20,21]$ have also worked with interactions and reactions of sulfur trioxide and ammonia not alone.

In our case, we recognize an ion of ammonia $\left(\mathrm{NH}_{3}^{+}\right)$in chitosan adsorbing an azoic dye with a sulfonate group ${ }^{-} \mathrm{O}_{3} \mathrm{~S}$. We calculated the adsorption energy among $\mathrm{NH}_{3}^{+}$and ${ }^{-} \mathrm{O}_{3} \mathrm{~S}$ molecular ions using molecular simulations.

\section{Methodology}

To study some characteristics of this molecular system, density functional theory (DFT) is used. The main advantage of this technique is to predict the geometry, band structure and cohesive energies of extended systems, without the need for external parameters Results as for ab initio semiempirical techniques. It is based on the ground state, having major problems in the study of excited states. The cal-

culations were accomplished using the DM $o l^{3}$ computer program proposed by Delley [22]. DM $o l^{3}$ was used to non-periodic structures with a generalized gradient approximation (GGA) to calculate the exchange-correlation potential and local potential gradient-corrected PW91. We use the DFT method with a set of DND numerical radial basis functions to calculate the interaction between groups

$\mathrm{NH}_{3}^{+}$and ${ }^{-} \mathrm{O}_{3} \mathrm{~S}$ [23]. Spin unrestricted orbital is used to solve Kohn-Sham equations when only one double bond is used in the sulfonate group ${ }^{-} \mathrm{O}_{3} \mathrm{~S}$. We accomplished calculations of connectivity which is a tool of DFT-DMol ${ }^{3}$ in order to get reactivity products.

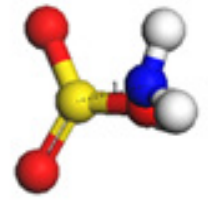

a)

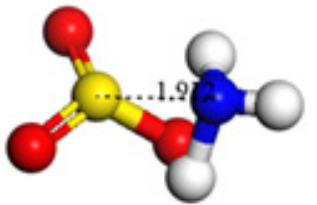

c)

Figure 2: a) Input: Distance $1.912 \AA$ among ${ }^{-} \mathrm{O}_{3} \mathrm{~S}$ sulfur oxide and ammonia ions in plane and pyramid geometry, respectively. b) Output: After the geometry optimization, growth of one OS bond and one ${ }^{\mathrm{NH}_{3}^{+}}$bond is observed. c) Input: Two double bonds of ${ }^{-} \mathrm{O}_{3} \mathrm{~S}$ sulfur oxide in a plane structure, and $\mathrm{NH}_{3}^{+}$ammonia ions in pyramid geometry. d) Output: growth of one OS bond and one $\mathrm{NH}$ bond 
Input-output geometry optimization of our molecules is observed in Figure 2. In the Input of Figure 2a, the $\mathrm{NH}_{3}^{+}$molecule has a pyramidal shape with its three hydrogen atoms in the same plane, while the ${ }^{-} \mathrm{O}_{3} \mathrm{~S}$ molecule has a planar shape; and an initial approach of $1.912 \AA$ among sulfur and nitrogen. The Output in Figure $2 \mathrm{~b}$ provides a small repulsion among the ion molecules with a distance of $3.093 \AA$ between sulfur and nitrogen, showing an increment of $62 \%$; an $83 \%$ increment of the SO bond length to $2.667 \AA$ and $94 \%$ of the NH bond length to $1.989 \AA$. The other two SO bonds in the ${ }^{-} O_{3} S$ molecule, now in a pyramidal shape, have a length of $1.48 \AA$, and the sulfur atom making SOO angles of $26.413^{\circ}, 28.776^{\circ}$ and $30.955^{\circ}$ with the plane in which the three oxygen atoms are located, while the $0 S 0$ angles are $117.923^{\circ}, 100.302^{\circ}$ and $91.536^{\circ}$. The mol-

ecule $\mathrm{NH}_{3}^{+}$has a pyramidal shape with three hydrogens in a plane making $\mathrm{NHH}$ angles of $27.836^{\circ}, 36.047^{\circ}$ and $26.863^{\circ}$, while HNH angles are $107.848^{\circ}, 88.026^{\circ}$ and $92.444^{\circ}$ respectively. The sizes of the NH bonds are $1.032 \AA$, $1.031 \AA$ and $1.989 \AA$. The Output in Figure
$2 \mathrm{~d}$ provides a small repulsion among the ion molecules with the distance of $3.404 \AA$ between sulfur and nitrogen, showing an increment of $78 \%$; an $68 \%$ increment of the SO bond length from $1.535 \AA$ to $2.584 \AA$ and $42 \%$ of the NH bond length from $1.362 \AA$ to $1.927 \AA$.

After geometry optimization of 29 steps when there is only one double bond on ${ }^{-}$, at a distance of $0.6816 \AA$ between $\mathrm{H}^{+}$and ${ }^{-} \mathrm{O}$ ions, an equilibrium point at the energy of $-654.471 \mathrm{kcal} / \mathrm{mol}$, and distance of $3.093 \AA ̊$ between $\mathrm{N}$ and S was obtained. A natural bond elongation corresponding to the ions of each molecule is observed. The optimization energy of sulfonate group ${ }^{-} O_{3} S$ is $-362.698 \mathrm{kcal} /$ mol and the optimization energy of the amino group protonated $\mathrm{NH}_{3}^{+}$is $-289.812 \mathrm{kcal} / \mathrm{mol}$. Then the adsorption energy is

$$
E_{a d}=E_{\mathrm{H}_{2} \mathrm{NOHSO}_{2}}-E_{-\mathrm{O}_{3} \mathrm{~S}}-E_{\mathrm{NH}_{3}^{+}}=18.119 \mathrm{kcal} / \mathrm{mol}
$$

which corresponds to weak chemisorption $[14,24]$. a)

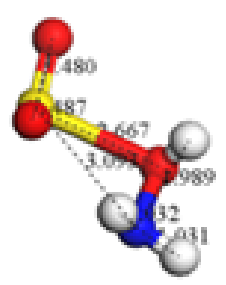

c)

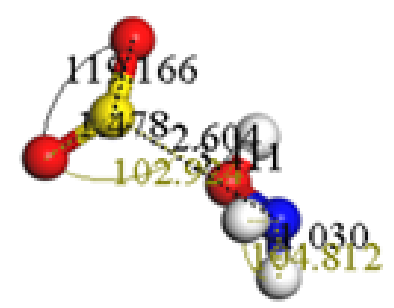

b)

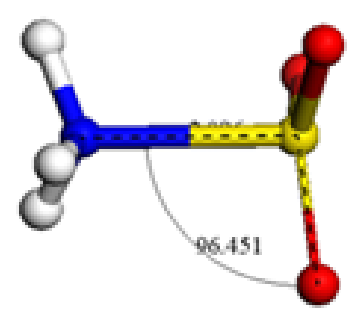

d)

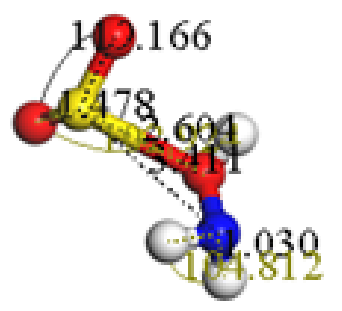

Figure 3: a) Neutral Acid form $\mathrm{H} 2 \mathrm{NOHSO} 2$ given a connectivity $0.6-1.51 \AA$. b) Zwitterion with connectivity $0.6-1.2 \AA$. c) There are two products for connectivity $0.6-1.15 \AA$. d) However, the Neutral Acid Form is again recovered for connectivity $0.6-1.51$.

Considering a nuclear NS equilibrium separation $\mathrm{R}=3.093 \AA$

for $\mathrm{NH}_{3} \mathrm{SO}_{3}$ molecule, and assuming that $\mathrm{NH}_{3}^{+}$and ${ }^{-} \mathrm{O}_{3} \mathrm{~S}$ ions possess spherically symmetric charge distributions, which up to that point no overlap has occurred, even if an elongation of the corresponding bonds to ions of each molecule is significant, where the spacing among such $\mathrm{H}^{+}$and ${ }^{-} \mathrm{O}$ ions is about $0.6816 \AA$. This value is obtained by measuring the bond distances: ${ }^{-} \mathrm{OH}^{+}, \mathrm{H}^{+} \mathrm{N}$, and $\mathrm{N}^{-} \mathrm{O}$ of a triangle of sides $0.987 \AA$, $1.989 \AA$ and $1.446 \AA$ respectively, with ${ }^{-} \mathrm{OH}^{+} \mathrm{N}$ angle $43.676^{\circ}$.

Since SO bond, before geometry optimization is $1.46 \AA$, when making a connectivity calculation with a tolerance of 0.6 to $1.507 \AA$ for the size of the bond, we see an oxygen of ${ }^{-} \mathrm{O}_{3} \mathrm{~S}$ molecular ion inserted into an $\mathrm{NH}$ bond of the ion of ammonia molecule without breaking molecules, therefore one $\mathrm{H}_{2} \mathrm{NOHSO}_{2}$ complex molecule is to be created through the complex $\mathrm{SO}_{3} \mathrm{NH}_{3}$ shown in Figure $2 \mathrm{~b}$, still needing connectivity. The entire dye molecule will be adsorbed on chitosan molecule without altering the distances at which they grew $3.093 \AA$ SO of the dye and $1.989 \AA$ NH of chitosan after a geometry optimization; evidently after a connectivity calculation the NH bond becomes two bonds: one $1.446 \AA$ NO and another $0.987 \AA$

$\mathrm{OH}$ with $108.2^{\circ} \mathrm{NOH}$ angle. Then $\mathrm{NH}$ and $\mathrm{OH}$ molecules share one electron occupying a stable orbital and making a covalent bond. This is the only case in which we have a neutral acid form $\mathrm{NH}_{2} \mathrm{SO}_{2} \mathrm{OH}$ through the isomer $\mathrm{HSO}_{3} \mathrm{NH}_{2}$ of sulfamic acid with covalent bonds as shown in Figure 3a, therefore there is chemisorp- 
tion due to the electronegativity of $\mathrm{H}, \mathrm{N}$, and $\mathrm{O}$ atoms. With the formation of a zwitterion as in Figure $3 \mathrm{~b}$ is not possible to clean water-pollution when dealing with chitosan, due to the orientation

of the ammonia ion $\mathrm{NH}_{3}^{+}$as part of it. In Figure 3c we applied connectivity $0.6-1.15 \AA$ and two products are obtained losing the double bond previously used in Figure $2 d$, however when connectivity $0.6-1.51 \AA$ is applied the neutral acid form is recovered with new characteristics. The most important are a reduction of $\mathrm{SO}$ bond to $2.604 \AA$ and new adsorption energy, now with optimization energy in which the sulfonate group ${ }^{-} O_{3} S$ gives $-362.698 \mathrm{kcal} /$

mol, the amino group protonated $\mathrm{NH}_{3}^{+}$gives $-289.812 \mathrm{kcal} / \mathrm{mol}$, and the neutral acid form gives $-658.388 \mathrm{kcal} / \mathrm{mol}$. Then:

$$
E_{a d}=E_{\mathrm{H}_{2} \mathrm{NOHSO}_{2}}-E_{-\mathrm{O}_{3} \mathrm{~S}}-E_{\mathrm{NH}_{3}^{+}}=14.110 \mathrm{kcal} / \mathrm{mol}
$$

\section{Discussion}

We have two structural models of ${ }^{-} \mathrm{O}_{3} S$ because we initially started working with only one double SO bond by considering satisfied the octet rule in this way. Then, we realized that several articles [25-29] have been working azo dye red 2 molecule using two So double bonds.

In these articles have been made investigation about:

a. Degradation of amaranth dye by using both TiO2-Zeolite Y catalyst and ion exchange sonocatalytic [25].

b. Amaranth adsorbed onto papaya seeds [26].

c. Pea and peanuts have been used to adsorb amaranth dye pollutant [27].

d. Embryotoxicity of amaranth red 2 in rats [28].

e. Adsorption removal of amaranth by nanoparticles-composed $\mathrm{Cu}_{2} \mathrm{O}$ microspheres [29].

The importance of removing this pollutant is evident after these statements, one more reason is that it is a histamine liberator and may intensify symptoms of asthma.

\section{Conclusion}

Applying DFT geometry optimization first to $\mathrm{NH}_{3}^{+}$ion, then to -O3S ion and finally to both molecular ions in a particular position take us to the isomer HSO3NH2 complex molecule which is neutral acid form $\mathrm{NH} 2 \mathrm{SO} 2 \mathrm{OH}$ of sulfamic acid, and it is chemisorption.

We present two possibilities of ${ }^{-} \mathrm{O}_{3} \mathrm{~S}$ ion, one of them is because we found it in this way in literature, and the other because when applying DFT connectivity it is considered with a single double bond, and in this case the adsorption energy is more chemisorbed. However, when this has two double bonds, the adsorption energy is less chemisorbed. These two adsorption energies remain in the threshold among physisorption and chemisorption, and we can say that the lowest adsorption energy is closer to physisorption than to chemisorption. $\mathrm{s}$

These two ions work as adsorbent and adsorbate active sites of chitosan and azoic dye molecules, respectively. Furthermore, chitosan has nutritious properties as food. Consequently, chitosan has the right properties to be used as natural food, favoring cleaning of pollutants in both water and the human body.

\section{References}

1. MA Wong, KB Wiberg, MJ Frisch (1992) Solvent effects. 2. Medium effect on the structure, energy, charge density, and vibrational frequencies of sulfamic acid. J Am Chem Soc 114(2): 523-529.

2. FA Kanda, A King (1951) Masthead. J Am Chem Soc 73: 2315.

3. RL Sass (1960) A Neutron Diffraction Study on the Crystal Structure of Sulfamic Acid. Acta Crystallogr 13: 320-324.

4. JW Bats, P Coppens, TF Koetzle (1977) Acta Crystallogr B 37: 1333.

5. A Reuven, D Marcellus, RS Parker, AL Kwiram (1981) J Chem Phys 74: 179.

6. LF Audrieth, M Sveda, HH Sisler, MJ Butler (1940) Sulfamic Acid, Sulfamide and related aquo-ammonosulfuric acids. Chem Rev 26: 49-94.

7. GA Benson, WJ Spillane (1980) Sulfamic acid and its N-substituted derivatives. Chem Rev 80(2): 151-186.

8. R Santmeyer, R Aarons (1969) in Kirk-Othmer Encyclopedia of Chemical Technology, A. Standem Interscience, New York, USA. 19: 242.

9. SJ Hickling, RG Woolley (1990) An ab initio Hartree-Fock study of the zwitterion of sulphamic acid, ${ }^{+} \mathrm{H}_{3} \mathrm{NSO}_{3}$. Chem Phys Lett 166(1): 43-48.

10.JE Douglas, GL Kenyon, PA Kollman (1978) The ammonia-sulfur trioxide interaction. An ab initio study. Chem Phys Lett 57(4): 553-556.

11. P Kaliannan, S Vishveswara, VSR Rao (1983) Ab initio SCF-MO study of the molecular structures of aminomethanol, aminesulfonic acid and N-methyl-sulfamate. J Mol Struct 105(3-4): 359-374.

12. DWJ Cruickshank (1985) A reassessment of $d \pi-p \pi$ bonding in the tetrahedral oxyanions of second-row atoms. J Molec Struct Eisentein 130(1-2): 177-191.

13. P Kaliannan, S Vishveswara, VSR Rao (1987) Current Sci 54: 111.

14. G Crini, PM Badot (2008) Application of Chitosan, a Natural Aminopolysaccharide, for Dye Removal from Aqueous Solutions by Adsorption Processes Using Batch Studies: A Review of Recent Literature. Prog Polym Sci 33: 399.

15. Q Liu, B Yang, L Zhang, R Huang (2015) Adsorption of an Anionic Azo Dye by Cross-Linked Chitosan/Bentonite Composite. Int J Biol Macromol 72: 1129-1135.

16. Kyzas GZ, Siafaka PI, Pavlidou EG, Chrissafis KJ, Bikiaris DN (2015) Synthesis and adsorption application of succinyl-grafted chitosan for the simultaneous removal of zinc and cationic dye from binary hazardous mixtures. Chem Eng J 259: 438-448.

17. NA Travlou, GZ Kyzas, NK Lazaridis, EA Deliyanni (2013) Chem Eng J 217: 256.

18. FR Alix, JL Duncan, Ch R McLamon (2003) US Patent No. US6605263 B2.

19. EM Hartley Jr, MJ Matteson (1975) Ind Eng Chem Fundam 14(1): 67.

20. M Solimannejad, A Boutalib (2004) G2 Molecular Orbital Investigation of $\mathrm{OC}^{+}-\mathrm{XH}, \mathrm{OCH}^{+}-\mathrm{X} 2$, and $\mathrm{OCH}^{+}-\mathrm{XY}(\mathrm{YX})(\mathrm{X}=\mathrm{Y}=\mathrm{F}, \mathrm{Cl}$, and $\mathrm{Br}$ ) Proton Bond Complexes. J Phys Chem 108: 10342.

21. P Antoniotti, S Borocci, F Grandinetti (2005) Comment on “Computational Investigation of $\mathrm{SO}_{3}-\mathrm{NH}_{3-\mathrm{n}} \mathrm{X}_{\mathrm{n}}(\mathrm{n}=0-3 ; \mathrm{X}=\mathrm{F}, \mathrm{Cl})$ Interactions". J Phys Chem 109(10): 2410-2411. 
22. B. Delley (2000) From molecules to solids with the DMol3 approach. J Chem Phys 113(18): 7756

23. A Pastor de Abram (2004) Quitina y Quitosano: obtención, caracterización y aplicaciones, Pontificia Universidad Católica del Perú / Fondo Editorial, Chile.

24. P Atkins, J Paula, (2010) Physical Chemistry. WH Freeman and Company, Novena Edición. New York, USA.

25. AH Alwash, AZ Abdullah, N Ismail (2013) TiO2-zeolite Y catalyst prepared using impregnation and ion-exchange method for sonocatalytic degradation of amaranth dye in aqueous solutionInternational Scholarly and Scientific Research \& Innovation 7(6): 375.
26. CT Weber, GC Collazzo, MA Mazutti, EL Foletto, GL Dotto (2014) Removal of hazardous pharmaceutical dyes by adsorption onto papaya seedsWater Science \& Technology 70(1): 102.

27. R Rehman, A Afzal (2015) Batch Scale Removal of an Organic Pollutant Amaranth Dye from Aqueous Solution using Pisum sativum Peels and Arachis hypogaea Shells as Adsorbents J Chem Soc Pak 37(5): 930.

28. TFX Collins, J McLaughlin, C Gray (1972) Fd Cosmet Toxicol 10: 619.

29. H Liao, Z Wang (2018) Adsorption removal of amaranth by nanoparticles composed Cu20 microspheres. Journal of Alloys and Compounds 769: 1088-1095. 